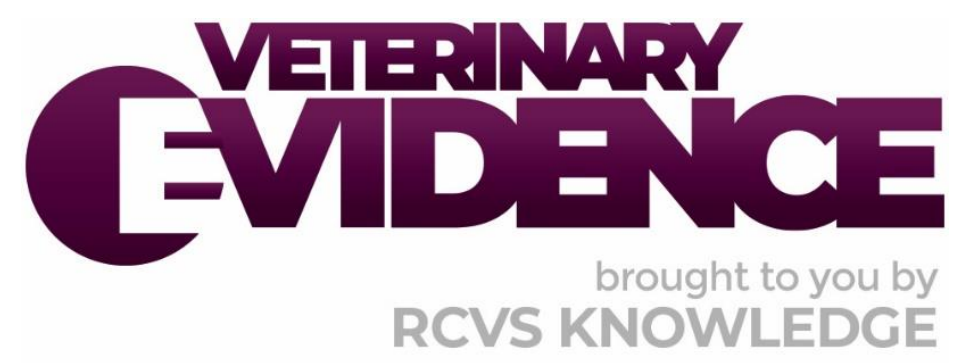

\title{
An assessment of the impact of educational interventions on hand hygiene compliance
}

A Knowledge Summary by

Carla Husband $\mathrm{BSc}$ (Hons) RVN ${ }^{1^{*}}$

Abbie McMillan BSc(Hons) RVN ${ }^{1}$

Lauren Sweeney BSc(Hons) RVN ${ }^{1}$

\footnotetext{
${ }^{1}$ University of Bristol, Senate House, Tyndall Ave, Bristol BS8 1TH

* Corresponding Author (ch16490@bristol.ac.uk)
}

ISSN: 2396-9776

Published: 16 Jul 2020

in: Vol 5, Issue 3

DOI: $10.18849 /$ VE.V5I3.320

Reviewed by: Myra Forster-van Hijfte (CertVR CertSAM DipECVIM-cA FRCVS) and Adam Swallow (BVSc MRCVS)

Next Review Date: 15 Oct 2021 


\section{KNOWLEDGE SUMMARY}

\section{PICO question}

In small animal veterinary professions, does implementation of an educational intervention, when compared to no intervention, improve hand hygiene compliance?

\section{Clinical bottom line}

\section{Category of research question}

Treatment

\section{The number and type of study designs reviewed}

Three papers were critically appraised. They were all prospective observational cohort studies

\section{Strength of evidence}

Weak

\section{Outcomes reported}

Two out of the three papers did not find educational implementation to have a statistically significant positive effect on hand hygiene compliance $(\mathrm{HHC})$ in small animal veterinary professionals

\section{Conclusion}

The veterinary evidence reviewed does not provide strong justification for the use of education in the improvement of HHC in small animal practice. This contrasts with extensive human evidence which supports the use of educational interventions (Helder et al., 2010). However, a limited veterinary knowledge base in the field of $\mathrm{HH}$, combined with the flawed methodologies of the appraised literature, suggests that this finding is not representative of the effect education could have on HHC.

The conclusion drawn from the evidence assessed within this Knowledge Summary is that educational interventions are not significantly linked to an improvement in $\mathrm{HHC}$ within a small animal veterinary setting. When considering the volume of human evidence which supports education as a tool to improve $\mathrm{HHC}$, the authors suggest this Knowledge Summary should be repeated in the future when additional veterinary evidence is available to reassess the conclusion drawn

\section{How to apply this evidence in practice}

The application of evidence into practice should take into account multiple factors, not limited to: individual clinical expertise, patient's circumstances and owners' values, country, location or clinic where you work, the individual case in front of you, the availability of therapies and resources.

Knowledge Summaries are a resource to help reinforce or inform decision-making. They do not override the responsibility or judgement of the practitioner to do what is best for the animal in their care. 


\section{Clinical Scenario}

The head nurse in a small animal veterinary practice has noticed a decline in hand hygiene compliance (HHC) within the team and wants to implement a strategy to improve this. They are unsure whether further education will influence $\mathrm{HHC}$ within the team. They have seen from human medicine studies that education increases compliance significantly and wants to see whether there is appropriate literature in the veterinary field to support the findings.

The aim of this Knowledge Summary is to appraise and consolidate veterinary research, so that veterinary professionals can understand the impact of educational interventions on HHC.

\section{The evidence}

All three articles, generated from scientific database searches, were retrieved from peer-reviewed and respectable scientific journals. Two studies, conducted by Smith et al. (2013) and Shea \& Shaw (2012), were based in teaching hospitals and focused on multimodal educational approaches. Shea \& Shaw (2012) provided a wholistic representation of HHC throughout various departments in the hospital, whereas, Smith et al. (2013) based the study in an intensive care unit. Similarities within methodology allowed for in-depth comparison of the two studies.

Anderson et al. (2014) utilised first opinion clinics as the sample population, therefore the results could be easily transferred into general practice, such as the clinical scenario. This study utilised recommended hand hygiene protocols to promote objective data collection at a recognised standard. The study methodology produced robust results that could be replicated further to aid protocol changes within practice.

All three studies demonstrated independent merits and limitations, however, the evidence provided by the articles collectively is not strong enough to recommend a change in clinical practice.

\section{Summary of the evidence}

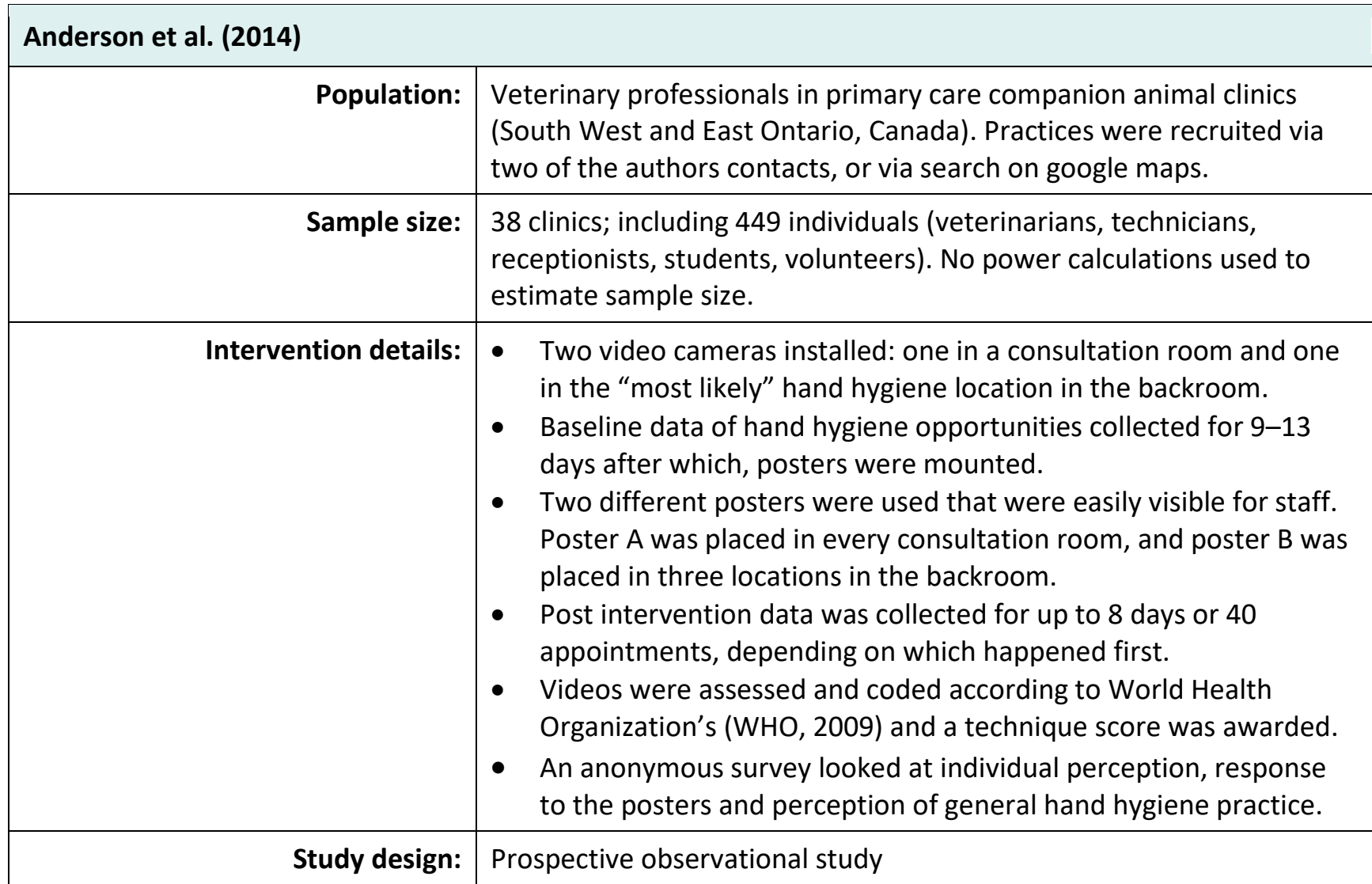




\begin{tabular}{|c|c|}
\hline Outcome studied: & $\begin{array}{l}\text { Primary variable related to PICO was poster implementation and its } \\
\text { impact on HHC. } \\
\text { Objective WHO guidelines were followed. } \\
\text { Mixed logistic regression and mixed linear regression were used to } \\
\text { perform statistical analysis. }\end{array}$ \\
\hline $\begin{array}{l}\text { Main findings: } \\
\text { (relevant to PICO question): }\end{array}$ & $\begin{array}{l}\text { - No significant effect of posters on } \mathrm{HHC} \text {. Odds ratio }=1.04,95 \% \\
\text { confidence interval and } p \text {-value }=0.5(p<0.05) \text {. Appropriate hand } \\
\text { hygiene conducted in } 14 \% \text { of opportunities. } \\
\text { Survey: } \\
\text { - } 272 / 289(94 \%) \text { of individuals noticed the posters. } \\
\text { - Individuals stated the posters improved their hand hygiene } \\
\text { awareness and practices (no figure given). }\end{array}$ \\
\hline Limitations: & $\begin{array}{l}\text { - Only one coder, which could result in observer bias, providing } \\
\text { subjective measurements. The coder could not be blinded to the } \\
\text { presence or absence of the posters. } \\
\text { Clinics were not randomly selected, which could lead to inherent } \\
\text { bias. } \\
\text { - No standardised time point when posters were installed, instead a } \\
\text { time range, therefore the data set was not consistent. } \\
\text { - Informed consent of filming gave potential rise to the Hawthorne } \\
\text { effect (Eckmanns et al., 2006). }\end{array}$ \\
\hline
\end{tabular}

\section{Smith et al. (2013)}

Population: Health care workers (HCWs): veterinary assistants, technicians, students, interns, residents and faculty at the intensive care unit (ICU) of a Veterinary Teaching Hospital at the University of Georgia, College of Veterinary Medicine.

Sample size: Uncontrolled due to staff movement, but interventions shown explicitly to $168 \mathrm{staff} /$ students. No power calculations used to estimate sample size required.

Intervention details: - Observation time period determined with a randomisation procedure. 10-15 hand hygiene opportunities measured each period.

- Over 12 weeks (-4 to -1 weeks for pre-intervention \& 1 to 8 weeks for post-intervention) a single observer made randomised observations of hand hygiene opportunities using the World Health Organization's guidelines and subsequent adherence (WHO, 2009).

- Pre-intervention observations conducted in week -3 to -2 and post-intervention in week 6 to 7 .

Intervention:

- Educational video on correct technique for hand hygiene presented three times during week 1 to $24 / 65$ (37\%) of residents, faculty and interns and to 100/103 (97\%) of incoming senior veterinary students who attended the presentation. The number of current senior veterinary students and technicians were not recorded. There is no explanation of how these individuals were 


\begin{tabular}{|c|c|}
\hline & $\begin{array}{l}\text { chosen to participate. } \\
25 \text { posters showcasing an adapted WHO educational campaign } \\
\text { were placed in different hospital locations and rotated every } 3 \\
\text { weeks. }\end{array}$ \\
\hline Study design: & Prospective observational study \\
\hline Outcome studied: & $\begin{array}{l}\text { - Hand hygiene adherence pre and post educational } \\
\text { implementation. } \\
\text { - Data collection was objective whilst following WHO guidelines } \\
\text { when deciding on appropriate opportunities/adherence. } \\
\text { - Statistical analysis was performed using a Fisher exact test to } \\
\text { compare the pre and post intervention hand hygiene adherence } \\
\text { demonstrated by the participants. }\end{array}$ \\
\hline $\begin{array}{l}\text { Main findings: } \\
\text { (relevant to PICO question): }\end{array}$ & $\begin{array}{l}\text { Pre-intervention: } 222 \text { observed hand hygiene opportunities, } 61 \\
\text { were appropriate (27\%). } \\
\text { - Post-intervention: } 249 \text { observed hand hygiene opportunities, } 73 \\
\text { were appropriate }(29 \%) \text {. } \\
\text { - No significant difference observed post intervention, } P=0.76 \\
\text { (p<0.05). No confidence intervals or effect size listed. }\end{array}$ \\
\hline Limitations: & $\begin{array}{l}\text { - The population was uncontrolled due to regular rotation of staff } \\
\text { members therefore individual improvement was unable to be } \\
\text { assessed. } \\
\text { - } \\
\text { Population who participated in educational intervention were not } \\
\text { necessarily observed in any of the data collection periods } \\
\text { - } \text { me hand-rub station by the entrance of ICU was not observed: } \\
\text { Hawthorne effect (Eckmanns et al., 2006): participants may have } \\
\text { changed their behaviour whilst being observed. } \\
\text { Post-intervention observations were not conducted until } 6 \text { weeks } \\
\text { post-intervention. The authors have suggested there was a } \\
\text { potential for a significant effect to be missed in the } \\
\text { undocumented period. However, education should induce a long- } \\
\text { lasting effect, so this may not be considered relevant. } \\
\text { - } 84 \% \text { of participants who received the intervention already had } \\
\text { extra hand hygiene training so this educational campaign may not } \\
\text { have been as impactful. }\end{array}$ \\
\hline
\end{tabular}

\section{Shea \& Shaw (2012)}

\begin{tabular}{|r|l|}
\hline Population: & $\begin{array}{l}\text { HCWs; faculty, interns, residents, students, technicians in Teaching } \\
\text { Hospital at the Cummings School of Veterinary Medicine, Tufts } \\
\text { University } \\
\text { Individuals of population were not controlled between pre- and post- } \\
\text { intervention results. }\end{array}$ \\
\hline Sample size: & $\begin{array}{l}\text { Baseline } \mathrm{n}=568 \text { hand hygiene opportunities, Post-intervention } \mathrm{n}= \\
103 \text { hand hygiene opportunities } \\
\text { Intervention events: Presentation } \mathrm{n}=48 \text { individuals; Online Module } \mathrm{n} \\
=103 \text { individuals }\end{array}$ \\
\hline Intervention details: & $\begin{array}{l}\text { Anonymous direct observation; assessed number of hand hygiene } \\
\text { opportunities and adequacy of hygiene for baseline and post- }\end{array}$ \\
\hline
\end{tabular}




\begin{tabular}{|c|c|}
\hline & $\begin{array}{l}\text { intervention data. } \\
\text { - Hanserved by various HCWs. } \\
\text { handling an animal. } \\
\text { Appropriate hand hygiene technique considered as either: } \\
\circ \quad \text { antibacterial foam } \\
\circ \quad \text { soap and water } \\
\circ \quad \text { wearing gloves and removing immediately after handling. } \\
\text { Baseline data collected over two weeks ( } 568 \text { hand hygiene } \\
\text { opportunities). } \\
\text { Authors reported baseline compliance rate to population } \\
\text { throughout campaign. } \\
\text { Campaign implemented over } 4 \text { weeks: } \\
\circ \quad \text { posters } \\
\circ \quad \text { signs } \\
\circ \text { presentation (voluntary and available to } 48 \text { individuals) } \\
\circ \quad \text { antibacterial foam slogans } \\
\circ \quad \text { intern/resident discussion at induction (mandatory) } \\
\circ \quad \text { online module (voluntary and available to } 103 \text { individuals). } \\
\text { Post-intervention data sampled } 2 \text { months after campaign } \\
\text { completion. } \\
\text { Baseline and post-intervention data collection was anonymous } \\
\text { and mandatory. }\end{array}$ \\
\hline Study design: & Prospective observational study \\
\hline Outcome studied: & $\begin{array}{l}\text { Baseline and post-intervention percentage of adequate hand } \\
\text { hygiene opportunities were compared. } \\
\text { - Data collected by multiple individuals through manual recording; } \\
\text { observer bias meant that data collection was subjective. } \\
\text { - Online module participation and presentation attendance were } \\
\text { recorded. } \\
\text { - Statistical analysis using Chi-squared test. }\end{array}$ \\
\hline $\begin{array}{l}\text { Main findings: } \\
\text { (relevant to PICO question): }\end{array}$ & $\begin{array}{l}\text { - There was a significant positive effect post educational } \\
\text { intervention: } \\
\text { - } \text { the population was } 4.2 \text { times (calculated using logistics } \\
\text { regression) as likely to use soap with water or antibacterial foam } \\
\text { post-intervention }(P=0.005) \\
\text { - } 20.6 \% \text { hand hygiene opportunities appropriate at baseline } \\
\text { compared to } 41.7 \% \text { hand hygiene opportunities appropriate post- } \\
\text { intervention }(P=0.001) \text {. } \\
\text { - } 20 / 48(41.7 \%) \text { of eligible population attended presentation. } \\
\text { - } 25 / 103(24.3 \%) \text { of eligible population completed module. } \\
\text { - Confidence interval and effect size not included. }\end{array}$ \\
\hline Limitations: & $\begin{array}{l}\text { - There was an uncontrolled sample size due to rotation of staff } \\
\text { members around the hospital. Therefore, individual improvement } \\
\text { was unable to be assessed. } \\
\text { - Post-intervention hand hygiene opportunities were less than } 1 / 3\end{array}$ \\
\hline
\end{tabular}




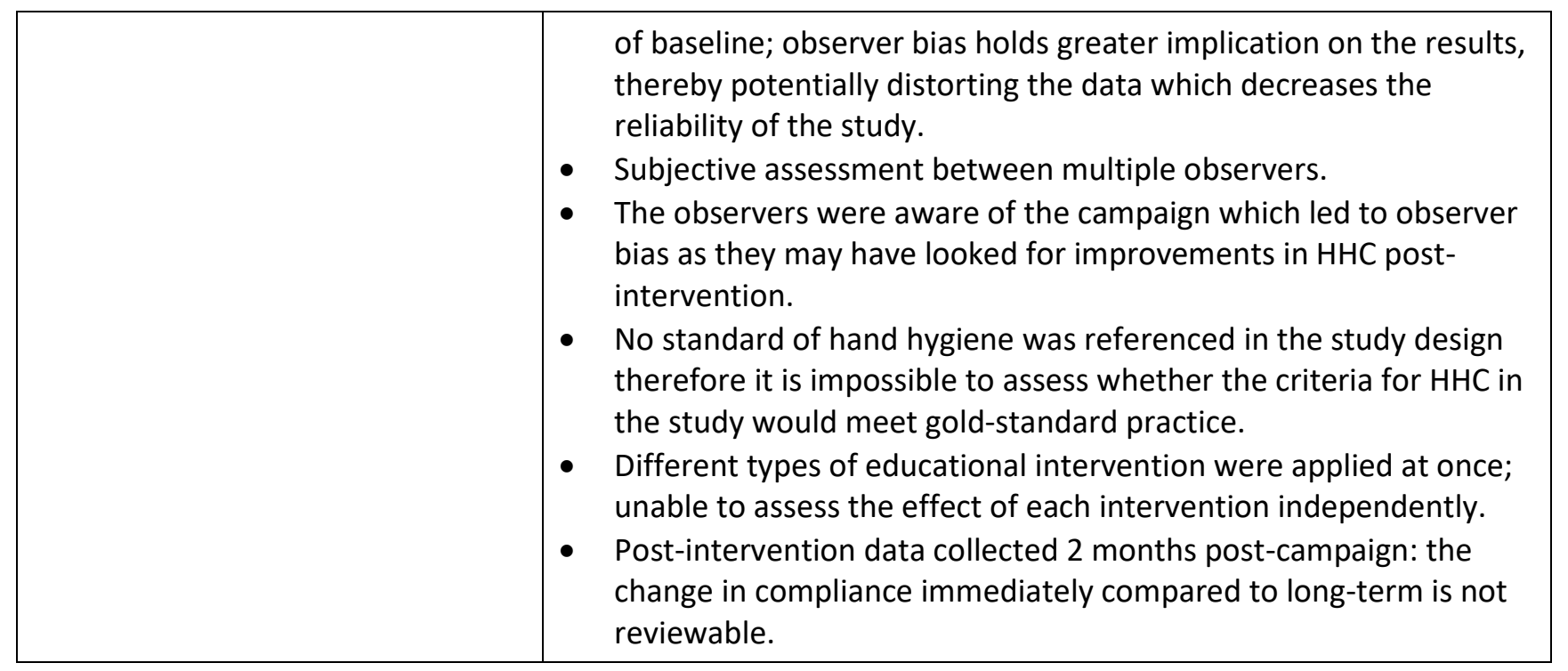

\section{Appraisal, application and reflection}

Helder et al. (2010) listed hand hygiene compliance (HHC) as a protective measure against nosocomial infections in human medicine and concludes that educational implementation has a statistically significant positive effect on HHC. Despite the stressed importance of HHC within human medicine (Randle et al., 2006), extensive database searches generated only three articles which answered the PICO; this displays a lack of veterinary evidence.

The study conducted by Anderson et al. (2014) showcased the highest transferability to general practice as the population consisted of first opinion clinics. Nevertheless, the authors used "known contacts" (Anderson et al., 2014) for recruitment. It was noted that the population who volunteered may have had a prior interest in hand hygiene, which could have exposed the results to inherent bias; this may have limited the true representation of the veterinary community.

The World Health Organization (WHO) deemed direct observation the most appropriate data collection method for assessment of HHC (WHO, 2019). Anderson et al. (2014) utilised video cameras to facilitate direct observation of participants to limit observation error. Pre-defined guidelines based on 'My 5 Moments for Hand Hygiene' (WHO, 2009) allowed objective quantification of hand hygiene opportunities. To gain informed consent the participants were briefed on the video camera purpose, therefore the Hawthorne effect may have elevated the compliance with hand hygiene protocols (Eckmanns et al., 2006). In a study that assessed HHC observation methodology, (Scherer et al. 2018) it was found that direct observation is subject to bias which can falsely increase the HHC rates observed when compared to a novel technique such as covert observations in 15 minute intervals, (Chang et al., 2016; Morgan et al., 2013; and Yin et al., 2014).

It is plausible to suggest that any improvement in HHC originally associated with the Hawthorne effect, (Eckmanns et al., 2006) may have been subject to habit formation due to progressive repetition (Kurz et al., 2015). Overall, Anderson et al. (2014) detected no significant post-intervention change. The article detailed extensive transparent statistical analysis such as logistic regression, odds ratio and confidence intervals, which were all appropriate assessments of the data provided and subsequently, increased reliability of results.

The two remaining studies by Shea \& Shaw (2012) and Smith et al. (2013) utilised similar methodology; both assessed the impact of a multimodal educational campaign on HHC and did not collect data immediately postintervention. Shea \& Shaw (2012) waited 2 months and Smith et al. (2013) waited 6 weeks. Both studies were set in teaching hospitals where regular staff rotation limited the ability to control the population; pre- and post-observations were not conducted on the same individuals so reproducibility of the results is limited. Shea 
\& Shaw (2012) found a statistically significant positive effect of the educational campaign on HHC. Despite the similarity in study design, Smith et al. (2013) did not discover a statistically significant effect; the absence of data collection immediately post-intervention was instead discussed as a limitation. Human medicine studies such as Dubbert et al. (1990) and Phan et al. (2018), have demonstrated the importance of obtaining immediate post-intervention data as well as delayed, to assess the effect of time on the impact of the educational interventions. The lack of justification of both methodologies may have compromised the result integrity. However, the statistical analysis applied, conducted with a Chi-squared test for Shea \& Shaw (2012) and a Fishers' exact test for Smith et al. (2013), was an appropriate assessment of the data.

Excluding Shea \& Shaw (2012), the two other studies used WHO (2009) guidelines of hand hygiene as an established measurement of compliance. Shea \& Shaw (2012) did not report which hand hygiene guidelines were used as the basis of study design, therefore comparison with the other articles is difficult. Human evidence, such as the WHO (2009) hand hygiene guidelines, is heavily relied upon to form veterinary hand hygiene protocols due to lack of veterinary evidence. Comparison was also difficult due to the differences in educational interventions between all three studies; it was not clear which aspect of the intervention had an effect on HHC. Further research could be conducted to compare individual educational approaches to find the most efficacious intervention.

The general techniques and opportunities for hand hygiene have been stated to be transferable between human and veterinary medicine, (Mann, 2017) using the One Health principle (Committee on the National Needs for Research in Veterinary Science et al., 2005). However, there is a current disparity between the human and veterinary evidence with regards to the effect of education on HHC (Helder et al., 2010). In addition, there is a lack of research which compares the motivational factors of HHC for human and veterinary care providers; therefore, it is difficult to determine whether the One Health concept should be applied to veterinary practice in the field of hand hygiene.

To validate the conclusions drawn by Shea \& Shaw (2012), further research is needed with application of a standardised, clinically relevant assessment of hand hygiene in veterinary medicine. The veterinary evidence reviewed does not provide strong justification for the use of education in the improvement of HHC in small animal practice. This contrasts with extensive human evidence which supports the use of educational interventions (Helder et al., 2010). However, a limited veterinary knowledge base in the field of hand hygiene, combined with the flawed methodologies of the appraised literature, suggests that this finding is not representative of the effect education could have on HHC. Until there is definitive assessment on the application of human hand hygiene research to veterinary medicine, it is recommended to utilise the results of this Knowledge Summary alongside the human evidence-base in order to improve HHC.

\section{Methodology Section}

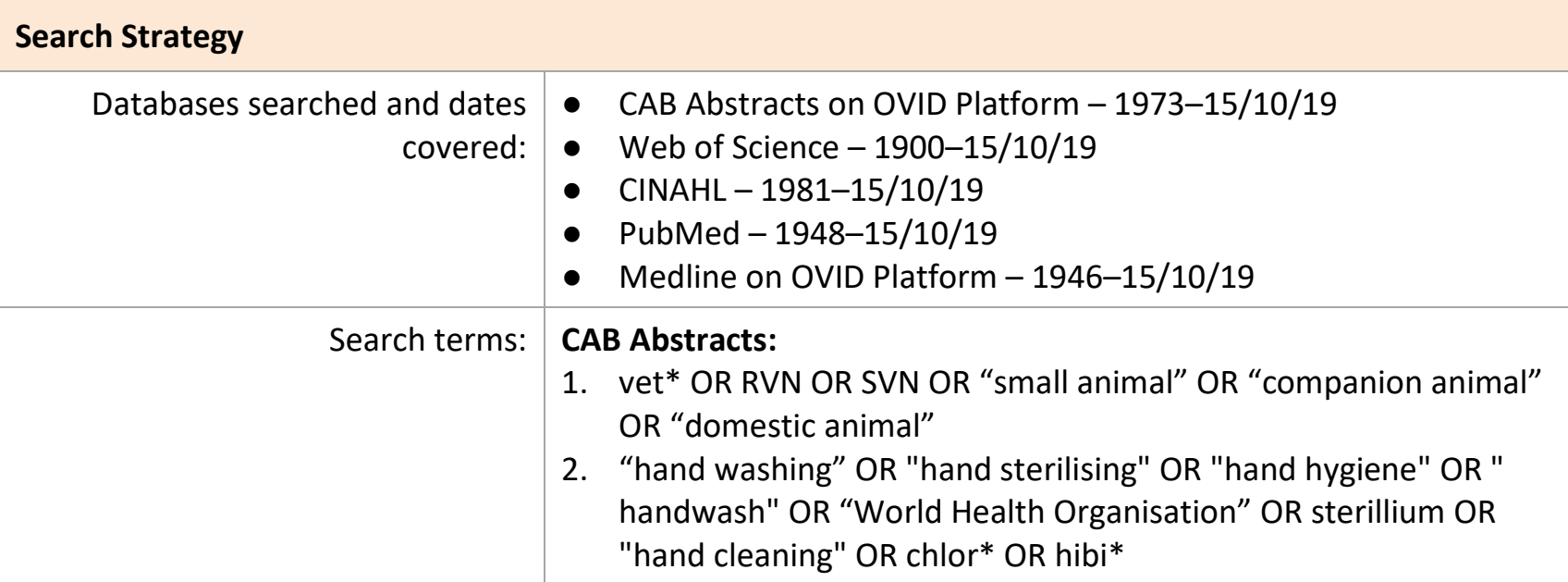




\begin{tabular}{|c|c|}
\hline &  \\
\hline Dates searches performed: & $15 / 10 / 2019$ \\
\hline
\end{tabular}

\section{Exclusion / Inclusion Criteria}

Exclusion: Does not answer PICO, not an experiment, duplicate

Inclusion: Answers PICO, small animal medicine based, English language 


\begin{tabular}{|c|c|c|c|c|c|}
\hline \multicolumn{6}{|l|}{ Search Outcome } \\
\hline Database & $\begin{array}{c}\text { Number of } \\
\text { results }\end{array}$ & $\begin{array}{c}\text { Excluded - } \\
\text { [Does not } \\
\text { answer PICO] }\end{array}$ & $\begin{array}{l}\text { Excluded - } \\
\text { [Not an } \\
\text { experiment] }\end{array}$ & $\begin{array}{l}\text { Excluded - } \\
\text { [Duplicate] }\end{array}$ & $\begin{array}{c}\text { Total relevant } \\
\text { papers }\end{array}$ \\
\hline CAB Abstracts & 27 & 23 & 1 & 0 & 3 \\
\hline Web of Science & 24 & 20 & 1 & 3 & 0 \\
\hline CINAHL & 19 & 19 & 0 & 0 & 0 \\
\hline PubMed & 92 & 89 & 0 & 3 & 0 \\
\hline Medline & 26 & 22 & 1 & 3 & 0 \\
\hline \multicolumn{5}{|c|}{ Total relevant papers } & 3 \\
\hline
\end{tabular}

\section{CONFLICT OF INTEREST}

The authors declare no conflicts of interest.

\section{REFERENCES}

1. Anderson, M., Sargeant, J. and Weese, J. (2014). Video observation of hand hygiene practices during routine companion animal appointments and the effect of a poster intervention on hand hygiene compliance. BMC Veterinary Research, 10(1), pp.106. DOI: https://doi.org/10.1186/1746-6148-10-106

2. Chang, N., Reisinger, H., Jesson, A., Schweizer, M., Morgan, D., Forrest, G. and Perencevich, E. (2016). Feasibility of monitoring compliance to the My 5 Moments and Entry/Exit hand hygiene methods in US hospitals. American Journal of Infection Control, 44(8), pp.938-940.

DOI: https://doi.org/10.1016/i.ajic.2016.02.007

3. Committee on the National Needs for Research in Veterinary Science, Board on Agriculture and Natural Resources, Division on Earth and Life Studies, and National Research Council (2005). The role of veterinary research in human society. Critical Needs for Research in Veterinary Science. National Academic Press. Washington, D.C. pp.13-20. DOI: https://doi.org/10.17226/11366

4. Dubbert, P., Dolce, J., Richter, W., Miller, M. and Chapman, S. (1990). Increasing ICU Staff Handwashing: Effects of Education and Group Feedback. Infection Control \& Hospital Epidemiology, 11(4), pp.191-193. DOI: https://doi.org/10.1086/646148

5. Eckmanns, T., Bessert, J., Behnke, M., Gastmeier, P. and Rüden, H., (2006). Compliance With Antiseptic Hand Rub Use in Intensive Care Units The Hawthorne Effect. Infection Control \& Hospital Epidemiology, 27(9), pp.931-934. DOI: https://doi.org/10.1086/507294 
6. Helder, O., Brug, J., Looman, C., van Goudoever, J. and Kornelisse, R. (2010). The impact of an education program on hand hygiene compliance and nosocomial infection incidence in an urban Neonatal Intensive Care Unit: An intervention study with before and after comparison. International Journal of Nursing Studies, 47(10), pp.1245-1252. DOI: https://doi.org/10.1016/i.ijnurstu.2010.03.005

7. Kurz, T., Gardner, B., Verplanken, B. and Abraham, C. (2014). Habitual behaviors or patterns of practice? Explaining and changing repetitive climate-relevant actions. Wiley Interdisciplinary Reviews: Climate Change, 6(1), pp.113-128. DOI: https://doi.org/10.1002/wcc.327

8. Mann, A. (2017). The importance of hand hygiene. Veterinary Nursing Journal, 32(3), pp.82-85. DOI: https://doi.org/10.1080/17415349.2016.1269624

9. Morgan, D., Pineles, L., Shardell, M., Graham, M., Mohammadi, S., Forrest, G., Reisinger, H., Schweizer, M. and Perencevich, E. (2013). The Effect of Contact Precautions on Healthcare Worker Activity in Acute Care Hospitals. Infection Control \& Hospital Epidemiology, 34(1), pp.69-73.

DOI: https://doi.org/10.1086/668775

10. Phan, H., Tran, H., Tran, H., Dinh, A., Ngo, H., Theorell-Haglow, J. and Gordon, C. (2018). An educational intervention to improve hand hygiene compliance in Vietnam. BMC Infectious Diseases, 18(1). DOI: https://doi.org/10.1186/s12879-018-3029-5

11. Randle, J., Clarke, M. and Storr, J. (2006). Hand hygiene compliance in healthcare workers. Journal of Hospital Infection, 64(3), pp.205-209. DOI: https://doi.org/10.1016/i.jhin.2006.06.008

12. Scherer, A., Reisinger, H., Goto, M., Goedken, C., Clore, G., Marra, A., Chasco, E., Evans, C., Rubin, M. and Perencevich, E. (2018). Testing a novel audit and feedback method for hand hygiene compliance: A multicenter quality improvement study. Infection Control \& Hospital Epidemiology, 40(1), pp.89-94. DOI: https://doi.org/10.1017/ice.2018.277

13. Shea, A. and Shaw, S. (2012). Evaluation of an educational campaign to increase hand hygiene at a small animal veterinary teaching hospital. Journal of the American Veterinary Medical Association, 240(1), pp.61-64. DOI: https://doi.org/10.2460/javma.240.1.61

14. Smith, J., Packman, Z. and Hofmeister, E. (2013). Multimodal evaluation of the effectiveness of a hand hygiene educational campaign at a small animal veterinary teaching hospital. Journal of the American Veterinary Medical Association, 243(7), pp.1042-1048.

DOI: https://doi.org/10.2460/javma.243.7.1042

15. World Health Organization (2009). My 5 Moments for Hand Hygiene.

16. World Health Organization (2019). WHO | Hand hygiene monitoring and feedback.

17. Yin, J., Reisinger, H., Weg, M., Schweizer, M., Jesson, A., Morgan, D., Forrest, G., Graham, M., Pineles, L. and Perencevich, E. (2014). Establishing Evidence-Based Criteria for Directly Observed Hand Hygiene Compliance Monitoring Programs: A Prospective, Multicenter Cohort Study. Infection Control \& Hospital Epidemiology, 35(9), pp.1163-1168. DOI: https://doi.org/10.1086/677629 


\section{EVIIDEFeE

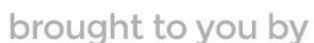 \\ RCVS KNOWLEDGE}

\section{Intellectual Property Rights}

Authors of Knowledge Summaries submitted to RCVS Knowledge for publication will retain copyright in their work, and will be required to grant RCVS Knowledge a non-exclusive license of the rights of copyright in the materials including but not limited to the right to publish, re-

publish, transmit, sell, distribute and otherwise use the materials in all languages and all media throughout the world, and to license or permit others to do so.

\section{Disclaimer}

Knowledge Summaries are a peer-reviewed article type which aims to answer a clinical question based on the best available current evidence. It does not override the responsibility

of the practitioner. Informed decisions should be made by considering such factors as individual clinical expertise and judgement along with patient's circumstances and owners' values. Knowledge Summaries are a resource to help inform and any opinions expressed within the Knowledge Summaries are the author's own and do not necessarily reflect the view of the RCVS Knowledge. Authors are responsible for the accuracy of the content. While the

Editor and Publisher believe that all content herein are in accord with current recommendations and practice at the time of publication, they accept no legal responsibility

for any errors or omissions, and make no warranty, express or implied, with respect to material contained within.

For further information please refer to our Terms of Use.

RCVS Knowledge is the independent charity associated with the Royal College of Veterinary Surgeons (RCVS). Our ambition is to become a global intermediary for evidence based veterinary knowledge by providing access to information

that is of immediate value to practicing veterinary professionals and directly contributes to evidence based clinical decision-making.

https://www.veterinaryevidence.org/

RCVS Knowledge is a registered Charity No. 230886.

Registered as a Company limited by guarantee in England and Wales No. 598443.

Registered Office: Belgravia House, 62-64 Horseferry Road, London SW1P 2AF

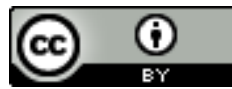

This work is licensed under a Creative Commons Attribution 4.0 International License 